\title{
EFFECT OF LOW TEMPERATURE ION IRRADIATION ON THE MICROSTRUCTURE OF NITRIDE CERAMICS
}

\author{
S.J. ZINKLE*, L.L. SNEAD*, W. S. EATHERLY* J.W. JONES* AND D.K. HENSLEY** \\ *Metals and Ceramics Division and **Solid State Division, Oak Ridge National Laboratory, \\ P.O. Box 2008, Oak Ridge, TN 37831-6376 USA, zinklesj@orni.gov
}

\section{ABSTRACT}

Cross-section transmission electron microscopy was used to investigate the microstructure of polycrystalline silicon nitride $\left(\mathrm{Si}_{3} \mathrm{~N}_{4}\right)$ and aluminum nitride (AIN) following $2 \mathrm{MeV} \mathrm{Si}$ ion irradiation at 80 and $400 \mathrm{~K}$ up to a fluence of $4 \times 10^{20}$ ions $/ \mathrm{m}^{2}$ (maximum damage of $\sim 10$ displacements per atom, dpa). A buried amorphous band was observed at both temperatures in $\mathrm{Si}_{3} \mathrm{~N}_{4}$ in the region corresponding to the peaks in the implanted ion and displacement damage. From a comparison of $\mathrm{Si}_{3} \mathrm{~N}_{4}$ specimens irradiated at different fluences, it is concluded that the amorphization is primarily controlled by the implanted $\mathrm{Si}$ concentration rather than the displacement damage level. $\mathrm{Si}_{3} \mathrm{~N}_{4}$ amorphization did not occur in regions well-separated from the implanted ions for doses up to at least $3 \mathrm{dpa}$ at $80 \mathrm{~K}$, whereas amorphization occurred in the ion implanted region (calculated $\mathrm{Si}$ concentration $>0.01$ at. \%) for damage levels as low as $\sim 0.6 \mathrm{dpa}$. The volumetric swelling associated with the amorphization of $\mathrm{Si}_{3} \mathrm{~N}_{4}$ is $<10 \%$. Amorphization was not observed in any of the irradiated AIN specimens. A moderate density of small $(-3 \mathrm{~nm})$ defect clusters were observed in the crystalline damaged regions of both the $\mathrm{Si}_{3} \mathrm{~N}_{4}$ and $\mathrm{AlN}$ specimens at both irradiation temperatures. Aligned network dislocations were also observed in the AIN specimen irradiated to high dose at $80 \mathrm{~K}$.

\section{INTRODUCTION}

AIN and $\mathrm{Si}_{3} \mathrm{~N}_{4}$ are being considered for numerous electronics and structural ceramic applications. Both of these materials have high strength and high electrical resistivity at moderate temperatures. Despite the widespread interest in these materials for technical applications; relatively little is known about their point defect behavior. We are unaware of any studies on self-interstitial atom (SIA) mobility in $\mathrm{Si}_{3} \mathrm{~N}_{4}$. Atobe and coworkers found that the nitrogen vacancies ( $\mathrm{F}$ centers) in AlN accumulated linearly with fast neutron fluence during irradiation at $20 \mathrm{~K}$, whereas the accumulation was sublinear (proportional to the square root of fluence) at $360 \mathrm{~K}$ [1]. This indicates [2] that nitrogen SIAs are immobile in AIN at $20 \mathrm{~K}$ and mobile at $360 \mathrm{~K}$.

Examination of the irradiated microstructure of ceramics, and in particular the temperaturedependent amorphization behavior, can provide insight into the mobility of point defects [3-5]. Several previous microstructural investigations of irradiated $A I N$ and $\mathrm{Si}_{3} \mathrm{~N}_{4}$ have been performed. Elevated temperature neutron irradiations of $\mathrm{AlN}$ [6,7] and $\mathrm{Si}_{3} \mathrm{~N}_{4}$, [8] have observed faulted dislocation loops on basal and prism habit planes, respectively. Amorphization did not occur during $1 \mathrm{MeV}$ electron irradiation at $140 \mathrm{~K}$ up to a fluence of $3 \times 10^{26} / \mathrm{m}^{2}(\sim 0.5 \mathrm{dpa})$ in AlN [9] or during $1-2 \mathrm{MeV}$ electron irradiation at $100-170 \mathrm{~K}$ up to fluences of $3-18 \times 10^{26} / \mathrm{m}^{2}(\sim 0.5-4 \mathrm{dpa})$ in $\mathrm{Si}_{3} \mathrm{~N}_{4}$ [9-11]. AlN and $\mathrm{Si}_{3} \mathrm{~N}_{4}$ were found to remain crystalline following room temperature bombardment with $3 \mathrm{MeV} \mathrm{Kr}$ ions up to a fluence of $2 \times 10^{21} / \mathrm{m}^{2}(\sim 150$ dpa peak damage $)$ [12]. Conversely, numerous ion irradiation studies at temperatures from 80 to $450 \mathrm{~K}$ have found that $\mathrm{Si}_{3} \mathrm{~N}_{1}$ can be amorphized after $\sim 1$ to $2 \mathrm{dpa}$ in the region corresponding to the peak in the implanted ion $(\mathrm{Ni}, \mathrm{Ti}, \mathrm{Si}, \mathrm{Fe}, \mathrm{Cr})$ and displacement damage profiles [3,13-17]. The discrepancy in the $\mathrm{Si}_{3} \mathrm{~N}_{4}$ amorphization behavior observed by Cartz et al. [12] and the implanted $\mathrm{Ni}, \mathrm{Ti}, \mathrm{Si}, \mathrm{Fe}, \mathrm{Cr}$ studies [3,13-17] highlights the importance of obtaining amorphization data under conditions where implanted ion effects are negligible [3]. Silicon nitride was recently shown to be resistant to amorphization up to $7 \mathrm{dpa}$ during room temperature $3.6 \mathrm{MeV} F$ ion irradiation in regions well separated from the implanted ions, whereas amorphization occurred readily in ion-implanted regions for doses of $\sim 2$ dpa [3]. Unfortunately, many ion beam amorphization studies have not attempted to separate implanted ion and displacement $q a$ ag effects, with the notable exceptions of in-situ thin foil [18] and cross-section $30 \mathrm{y}$ tion it wation studies. 


\section{DISCLAIMER}

This report was prepared as an account of work sponsored by an agency of the United States Government. Neither the United States Government nor any agency thereof, nor any of their employees, make any warranty, express or implied, or assumes any legal liability or responsibility for the accuracy, completeness, or usefulness of any information, apparatus, product, or process disclosed, or represents that its use would not infringe privately owned rights. Reference herein to any specific commercial product, process, or service by trade name, trademark, manufacturer, or otherwise does not necessarily constitute or imply its endorsement, recommendation, or favoring by the United States Government or any agency thereof. The views and opinions of authors expressed herein do not necessarily state or reflect those of the United States Government or any agency thereof. 


\section{DISCLAIMER}

Portions of this document may be illegible in electronic image products. Images are produced from the best available original document. 
Table 1. Summary of properties of the investigated $A I N$ and $S i_{2} N_{4}$ ceramics [7.19].

\begin{tabular}{|c|c|c|c|c|c|c|}
\hline Material & $\begin{array}{c}\text { Crystal } \\
\text { structure }\end{array}$ & $\begin{array}{c}\text { Lattice } \\
\text { parameters }\end{array}$ & $\begin{array}{c}\text { Density } \\
\left(\mathrm{g} / \mathrm{cm}^{3}\right)\end{array}$ & $\begin{array}{c}\text { Thermal } \\
\text { conductivity } \\
(\mathrm{W} / \mathrm{m}-\mathrm{K})\end{array}$ & Ionicity & $\begin{array}{l}\text { Sublimation } \\
\text { temperature }\end{array}$ \\
\hline $\begin{array}{c}\text { AlN } \\
(\mathrm{Cercom})\end{array}$ & $\begin{array}{c}\text { Hexagonal } \\
\text { (wurtzite) }\end{array}$ & $\begin{array}{c}\mathrm{a}=0.311 \mathrm{~nm} \\
\mathrm{c}=0.498 \mathrm{~nm} \\
\mathrm{c} / \mathrm{a}=1.60\end{array}$ & 3.25 & 115 & 0.40 & $2790 \mathrm{~K}$ \\
\hline $\begin{array}{c}\beta-\mathrm{Si}_{3} \mathrm{~N}_{4} \\
(\mathrm{Kyocera})\end{array}$ & $\begin{array}{c}\text { Hexagonal } \\
\text { (P6 } \\
\text { group) }\end{array}$ & $\begin{array}{c}\mathrm{a}=0.760 \mathrm{~nm} \\
\mathrm{c}=0.290 \mathrm{~nm} \\
\mathrm{c} / \mathrm{a}=0.290\end{array}$ & 3.21 & 29 & 0.28 & $2151 \mathrm{~K}$ \\
\hline
\end{tabular}

\section{EXPERIMENTAL PROCEDURE}

Small blocks of hot isostatically pressed $\mathrm{Si}_{3} \mathrm{~N}_{4}$ (Kyocera SN733) and sintered AIN (Cercom) were obtained from commercial vendors. Table 1 summarizes some of the physical properties of AlN and $\mathrm{Si}_{3} \mathrm{~N}_{4}[7,19]$. Transmission electron microscope (TEM) specimens ( $3 \mathrm{~mm}$ diameter by $0.5 \mathrm{~mm}$ thick) were machined by a combination of diamond sawing and ultrasonic cutting. The top surfaces of the specimens were mechanically polished using $0.05 \mu \mathrm{m}$ diamond paste.

The specimens were thermally anchored to a copper block using either silver paint or Aquadag ${ }^{\mathrm{TM}}$ adhesive. Duplicate specimens of each material were simultaneously irradiated for each irradiation condition using a $1.2 \mathrm{~cm}$ diameter beam spot. The irradiatic = were performed using 2 MeV Si beam currents of 0.3-1 $\mu \mathrm{A} / \mathrm{cm}^{2}$ at the Surface Modificatic . . -... Characterization (SMAC) facility in the Solid State Division at ORNL. The irradiatin temperature was continuously monitored by a thermocouple embedded in the support bi $-\mathrm{k}$. The maximum calculated beam heating was $<1^{\circ} \mathrm{C}$. Specimens were irradiated to fluences of etther $4 \times 10^{19}$ or $4 \times 10^{20} / \mathrm{m}^{2}$ at $78-82 \mathrm{~K}$ and $400 \mathrm{~K}$. The displacement damage and implanted ion profiles were calculated using the TRIM96 program [20]. Figure 1 shows the calculated results for $\Sigma_{3} \mathrm{~N}_{4}$; similar profiles were calculated for AIN. All calculations assumed a sublattice-averaged displacement energy of $40 \mathrm{eV}$.

Following the irradiation, cross-section TEM specimens were prepared by gluing the irradiated disks to polished unirradiated disks, sectioning, grinding to $0.1 \mathrm{~mm}$. dimpling to $20 \mu \mathrm{m}$, and then dual-gun ion beam thinning at $\sim 80 \mathrm{~K}$ with $6 \mathrm{keV}$ Ar ions until perforation occurred near the interface. The specimen surfaces were cleaned using $3 \mathrm{keV} \mathrm{Ar}$ ions at an angle of $11^{\circ}$ and then coated with a thin $(\sim 5 \mathrm{~nm})$ layer of carbon prior to examination. The specimens were examined using conventional bright-field and dark-field imaging techniques in a Philips CM-30 microscope operating at $300 \mathrm{kV}$.

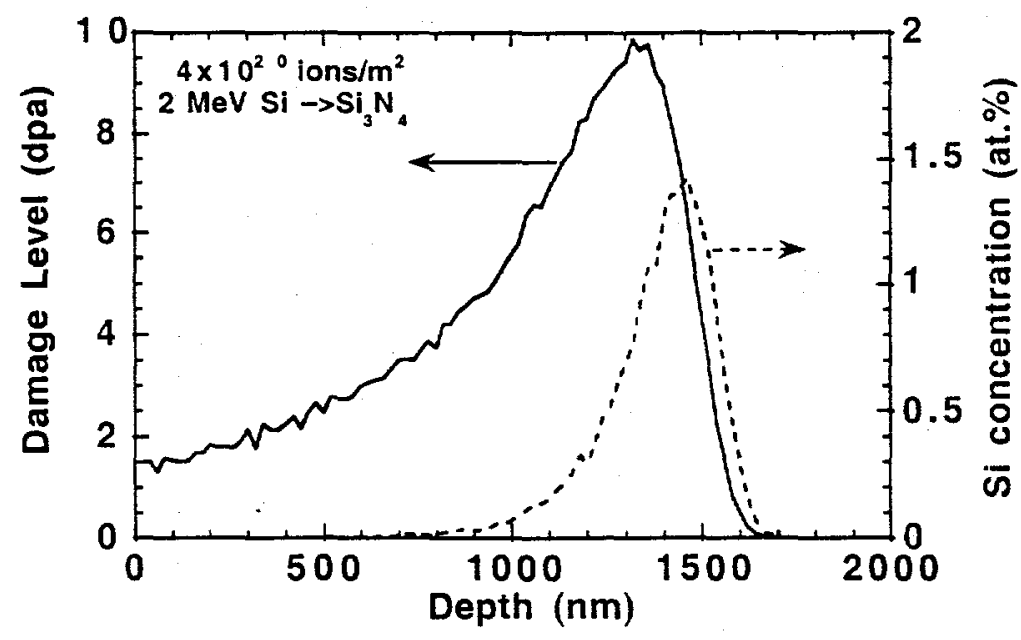

Fig. 1. Calculated damage and implanted ion distributions for $2 \mathrm{MeV}$ Si ions in $\mathrm{Si}_{3} \mathrm{~N}_{4}$. 


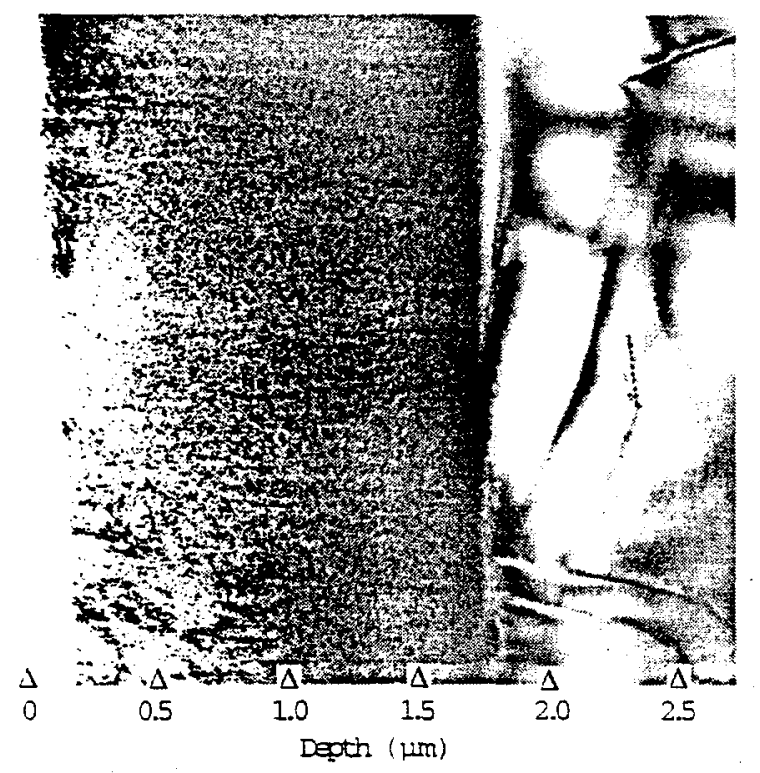

Fig. 3. Cross-section microstructure of aluminum nitride irradiated with $2 \mathrm{MeV} \mathrm{Si}$ ions at $78 \mathrm{~K}$ to a fluence of $4 \times 10^{20}$ ions $/ \mathrm{m}^{2}$.
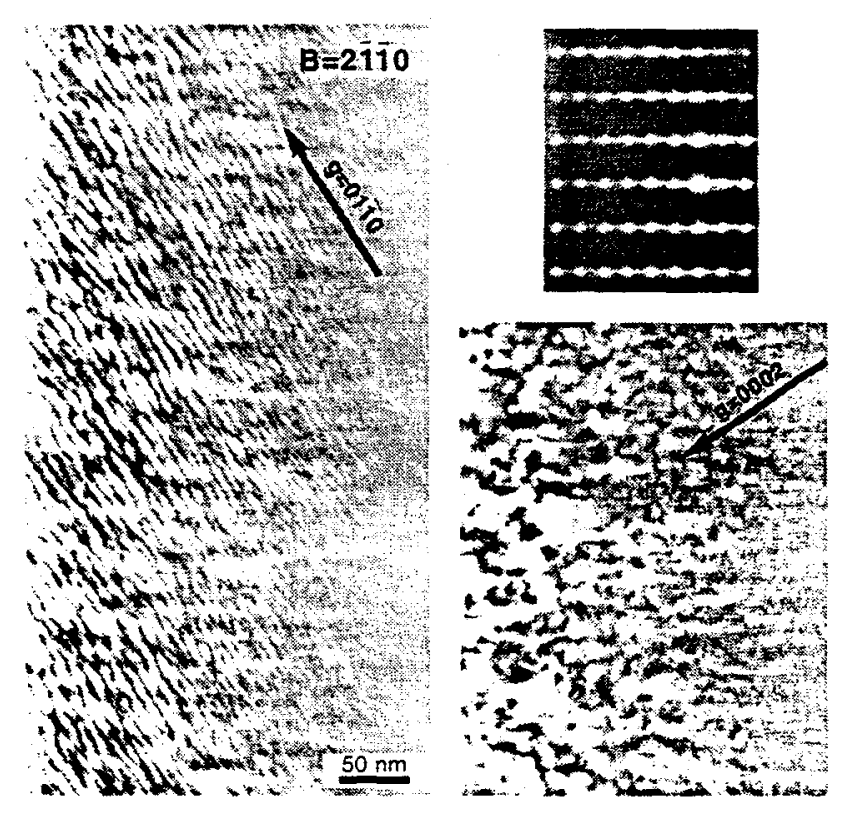

Fig. 4. Aligned network dislocations and defect clusters in AIN irradiated at $78 \mathrm{~K}$ to a fluence of $4 \times 10^{20}$ ions $/ \mathrm{m}^{2}$.

Figure 3 shows the general cross-section microstructure of aluminum nitride irradiated at $78 \mathrm{~K}$ to a fluence of $4 \times 10^{20}$ ions $/ \mathrm{m}^{2}$. A high density of small defect clusters (mean diameter of $\sim 3$ $\mathrm{nm}$ ) was formed up to a maximum depth of $1.74 \mu \mathrm{m}$. with no evidence for amorphous regions in the grain interior ( $\sim 8 \mu \mathrm{m}$ grain diameter). A similar damage range and defect microstructure was observed in the specimen irradiated at $400 \mathrm{~K}$ to the same fluence. The initially crystalline grain boundary phase in AIN (easily visible at grain boundary triple points) was amorphized during irradiation at $78 \mathrm{~K}$.

The irradiated microstructure of AIN is shown in finer detail in the centered dark field images of Fig. 4. A network of aligned dislocations were visible with a diffraction vector of $\mathrm{g}=01 \overline{\mathrm{I}} 0$ but were not present for $\mathrm{g}=0002$. Streaking was observed along the 0002 systematic row in the diffraction pattern.

\section{DISCUSSION}

According to ionicity model for amorphization susceptibility [22], $\mathrm{Si}_{3} \mathrm{~N}_{4}$ and AIN would both be expected to have moderate resistance to radiation-induced amorphization due to their largely covalent bonding. However, both of these materials have an amorphization resistance at $80 \mathrm{~K}$ that is comparable or superior to the predominantly ionic bonded $\mathrm{Al}_{2} \mathrm{O}_{3}$ which is amorphized after $\sim 5$ dpa $[23,24]$. Similarly, according to structural freedom considerations [25], $\mathrm{Si}_{3} \mathrm{~N}_{4}$ should become amorphous at lower doses than $\mathrm{Al}_{2} \mathrm{O}_{3}$. As discussed elsewhere, point defect mobility is another 
important factor for amorphization [4]. In particular, amorphization generally does not occur in irradiated ceramics if the anion and cation SIAs are mobile.

The observation of a well-developed network disiocation structure in AIN at $80 \mathrm{~K}$ (Fig. 4) is evidence for significant SIA mobility. This conclusion is based on the assumption that the network dislocation structure was formed by the growth and unfaulting of interstitial dislocation loops produced at lower doses. As discussed in the introduction, the earlier optical absorption study by Atobe et al. [1] suggested that nitrogen SIAs in AIN are immobile at $20 \mathrm{~K}$ and mobile at $360 \mathrm{~K}$. The present microstructural observations suggest that both the anion and cation interstitials in ion irradiated AIN are mobile at a temperature as low as $80 \mathrm{~K}$. Further work is needed to determine if there is any possible influence of ionization induced diffusion [26] which could produce enhanced point defect mobility during ion irradiation.

There is a lack of microstructural data to which the present low-temperature irradiation results can be compared. It is interesting to note that the predominant habit plane for dislocation loops observed in previous high-temperature neutron irradiation studies were [0001] and $\{10 \overline{1} 0\}$ for AlN and $\mathrm{Si}_{3} \mathrm{~N}_{4}$, respectively $[7,8]$. This difference may be due to the large difference in c/a lattice parameter ratios for these two materials (Table 1). The microstructural evolution in AIN irradiated to $\sim 10 \mathrm{dpa}$ at $80 \mathrm{~K}$ in the present study appeared to be more advanced than in a previous neutron irradiation study to a similar dose at $\sim 770 \mathrm{~K} \mathrm{[7].} \mathrm{The} \mathrm{neutron} \mathrm{irradiation} \mathrm{study} \mathrm{reported} \mathrm{the}$ presence of interstitial dislocation loops on the basal plane with a Burgers vector of $c / 2[0001]$, but a network dislocation structure was not observed. The formation of network dislocations in irradiated materials generally requires high doses at elevated temperatures. Work is in progress to investigate the dose and temperature dependence of the microstructure of ion-irradiated AIN.

As summarized in the introduction, there are no known observations of amorphization in AIN, although relatively few studies have been performed $[9,12]$. In contr- amerous studies have reported ion beam amorphization of $\mathrm{Si}_{3} \mathrm{~N}_{4}$. The results of th. esent study and ref. [3] demonstrate that certain implanted ions have a pronounced effe i promoting amorphization of $\mathrm{Si}_{3} \mathrm{~N}_{4}$. One possible mechanism for the implanted ion effeci is that the impurity atoms may effectively trap migrating SIAs in $\mathrm{Si}_{3} \mathrm{~N}_{4}$. The physical reason why AlN $: \Xi$ able to accommodate $>1 \% \mathrm{Si}$ without amorphization whereas $\mathrm{Si}_{3} \mathrm{~N}_{4}$ becomes amorphou : or implanted metal ion concentrations above 0.01-0.1 at.\% is worthy of further study. Fin the present study and previous work, strong implanted ion effects on the amorphization of $\mathrm{Si}_{3} \mathrm{~N}_{4}$ appear to exist for $\mathrm{Ni}$, $\mathrm{Ti}, \mathrm{Si}, \mathrm{Fe}$, and $\mathrm{Cr}$ ions [3,13-17]. Amorphization has not been observed in $\mathrm{Si}_{3} \mathrm{~N}_{4}$ irradiated at room temperature to moderate (3.5 dpa) or high (150 dpa) damage levels with $\mathrm{He}[3]$ or $\mathrm{Kr}$ [12] ions, respectively.

\section{CONCLUSIONS}

Aluminum nitride exhibits a high resistance to ion beam amorphization at temperatures as low as $80 \mathrm{~K}$. The pronounced microstructural evolution of the defect clusters in the irradiated AIN specimens suggests that there is high mobility of the self interstitial atoms on both sublattices at 80 $\mathrm{K}$. Therefore, amorphization is not expected to occur at temperatures $\geq 80 \mathrm{~K}$ even at higher doses (>10 dpa) unless implanted ions begin to trap point defects or the composition becomes significantly different from AIN due to the implanted ions.

The amorphization of beta-silicon nitride is extremely sensitive to small concentrations of implanted ions ( $\mathrm{Cr}, \mathrm{Ti}, \mathrm{Fe}, \mathrm{Si}$ ). Amorphization at $80 \mathrm{~K}$ occurred when the implanted $\mathrm{Si}$ concentration exceeded $\sim 100$ appm for damage levels greater than $\sim 0.5 \mathrm{dpa}$. Amorphization did not occur at $80 \mathrm{~K}$ outside of the implanted ion region $\left(\mathrm{c}_{\mathrm{si}}<100 \mathrm{appm}\right)$ for damage levels as high as 3 dpa. Amorphization at $400 \mathrm{~K}$ was also sensitive to the implanted ion concentration, with a critical concentration of $\mathrm{Si}$ needed to induce amorphization of $\sim 0.1$ at. \% for damage levels $>0.9$ dpa.

The development of resolvable defect clusters (and a network dislocation structure in the case of AIN) during irradiation at $\sim 80 \mathrm{~K}$ is an indication that both anion and cation self-interstitial atoms

are mobile in these two nitride ceramics. Further work at temperatures $<80 \mathrm{~K}$ is needed to determine the migration kinetics of self-interstitial atoms in these materials. 


\section{RESULTS}

Figure 2 shows the general cross-section microstructure of silicon nitride irradiated at $80 \mathrm{~K}$ to fluences of $4 \times 10^{19}$ and $4 \times 10^{20}$ ions $/ \mathrm{m}^{2}$. A buried amorphous band was observed at both fluences, with a width of $0.7 \mu \mathrm{m}$ at the lower fluence and $1.0 \mu \mathrm{m}$ at the higher fluence. The residual dark contrast in the amorphous regions is due to $\mathrm{Y}_{2} \mathrm{O}_{3}$-enriched grain boundaries $(0.5 \mu \mathrm{m}$ mean grain diameter). The amorphization dose was comparable at grain boundaries and in the grain interior. The measured maximum damage range at both fluences was $1.70 \pm 0.02 \mu \mathrm{m}$. The similarity in damage range for the two doses implies that the volumetric swelling associated with amorphization of $\mathrm{Si}_{3} \mathrm{~N}_{4}$ is $<10 \%$, which is much less than the value of $22-25 \%$ suggested in some previous ion irradiation studies $[15,16]$. A recent modeling study found that the crystalline and amorphous $\mathrm{Si}_{3} \mathrm{~N}_{4}$ densities were comparable [21], in agreement with the present results. From a comparison with the calculated TRIM profiles (Fig. 1), amorphization occurred at $80 \mathrm{~K}$ when the damage level was $>0.6 \mathrm{dpa}$ and the implanted $\mathrm{Si}$ concentration was $\mathrm{c}_{\mathrm{Si}}>0.01$ at. $\%$ in the lower fluence specimen and when the damage level was $>3.3 \mathrm{dpa}$ and $\mathrm{c}_{\mathrm{si}}>0.01$ at. $\%$ in the higher fluence specimen. This implies that the implanted ion concentration is the controlling factor in the low temperature amorphization of $\mathrm{Si}_{3} \mathrm{~N}_{4}$ (for damage levels $>0.6 \mathrm{dpa}$ ).

Smail defect clusters $(-3 \mathrm{~nm}$ diameter) were visible in the crystalline damaged regions of $\mathrm{Si}_{3} \mathrm{~N}_{4}$ irradiated at $80 \mathrm{~K}$ to a fluence of $4 \times 10^{20}$ ions $/ \mathrm{m}^{2}$, whereas these defect clusters were not visible in the lower fluence specimen. This implies that these defect clusters were formed as the result of nucleation and growth (or perhaps multiple overlapping cascades), as opposed to direct formation within a single cascade.

Irradiation of $\mathrm{Si}_{3} \mathrm{~N}_{4}$ at $400 \mathrm{~K}$ also produced a buried amorphous layer, although the band width at a given fluence was smaller than at $80 \mathrm{~K}$. For example, the amorphous layer was $\sim 0.17$ $\mu \mathrm{m}$ wide for irradiation at $400 \mathrm{~K}$ to a fluence of $4 \times 10^{19}$ ions $/ \mathrm{m}^{2}$. Analysis of the amorphization behavior at $400 \mathrm{~K}$ showed a good correlation with implanted $\mathrm{Si}$ concentration and a poor correlation with damage level. Amorphization of $\mathrm{Si}_{3} \mathrm{~N}_{4}$ at $400 \mathrm{~K}$ occurred when the calculated $\mathrm{Si}$ concentration exceeded 0.1 at.\% (for damage levels $>0.9$ dpa). Small defect clusters $(\sim 3 \mathrm{~nm}$ diameter) were observed in the damaged crystalline regions of $\mathrm{Si}_{3} \mathrm{~N}_{4}$ at both of the $400 \mathrm{~K}$ irradiation fluences.

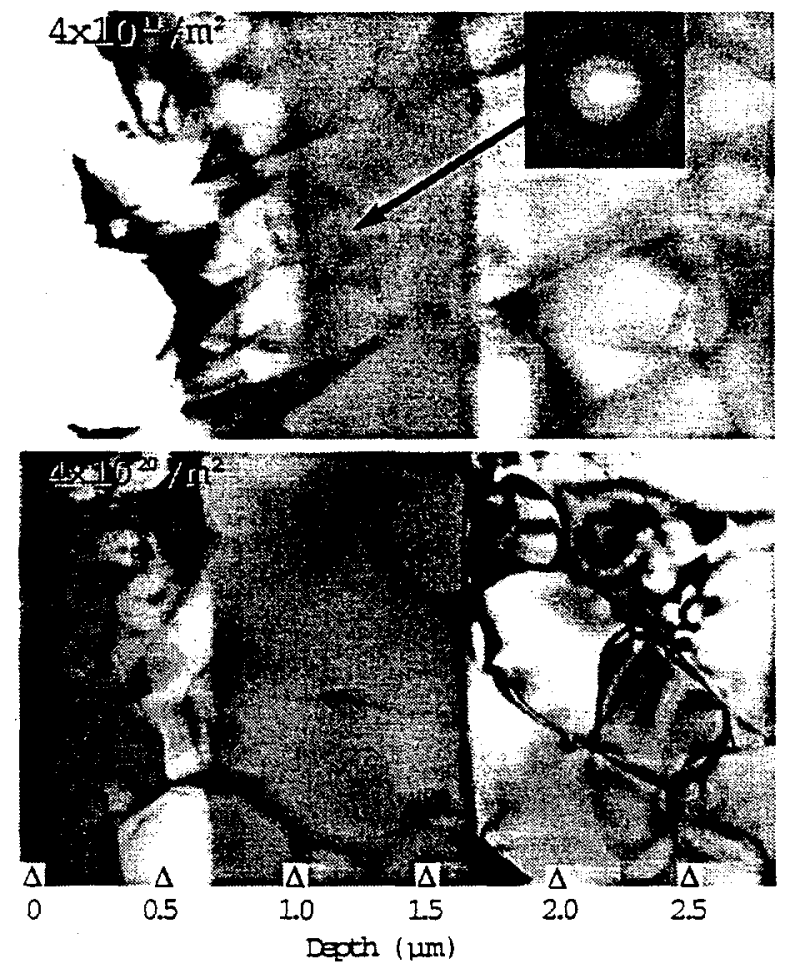

Fig. 2. Cross-section microstructures of $\mathrm{Si}_{3} \mathrm{~N}_{4}$ irradiated with $2 \mathrm{MeV}$ Si ions at $80 \mathrm{~K}$. 


\section{Acknowledgements}

This research was sponsored by the Office of Fusion Energy Sciences, U.S. Department of Energy under contract DE-AC05-960R22464 with Lockheed Martin Energy Research Corp.

\section{REFERENCES}

1. K. Atobe, M. Honda, N. Fukuoka, M. Okada, and M. Nakagawa, Jap. J. Appl. Phys. 29 (1), $150(1990)$.

2. S.J. Zinkle and C. Kinoshita, J. Nucl. Mater. 251, 200 (1997).

3. S.J. Zinkle and L.L. Snead. Nucl. Instr. Meth. B 116, 92 (1996).

4. S.J. Zinkle and G.P. Pells, J. Nucl. Mater. 253, 120 (1998).

5. A. Meldrum, S.J. Zinkle, L.A. Boatner, and R.C. Ewing, Phys. Rev. B, in press (1999).

6. T. Yano, M. Tezuka, H. Miyazaki, and T. Iseki, J. Nucl. Mater. 191-194, 635 (1992).

7. T. Yano and T. Iseki, J. Nucl. Mater. 203, 249 (1993).

8. R.A. Youngman and T.E. Mitchell, Radiat. Eff. 74. 267 (1983).

9. A. Matsunaga, C. Kinoshita, K. Nakai, and Y. Tomokiyo, J. Nucl. Mater. 179-181, 457 (1991).

10. H. Inui, H. Mori, and H. Fujita. Acta Metall. 37 (5), 1337 (1989).

11. H. Mori, T. Sakata, H. Yasuda, and M. Maeda. J. Vac. Sci. Technol. B 12 (4), 2376 (1994).

12. L. Cartz, F.G. Karioris, and R.A. Fournelle, Radiat. Eff. 54. 57 (1981).

13. R.S. Bhattacharya, A.K. Rai, and P.P. Pronko. J. Appl. Phys. 61 (10), 4791 (1987).

14. R.G. Vardiman, in Processing and Charaterization of Materials using Ion Beams, MRS Symposium Proceedings, edited by L.E. Rehn. J. Greene, and F.A. Smidt (Materials Research Society, Pittsburgh, 1989), Vol. 128, p. 369.

15. W. Bolse, S.D. Peteves, and F.W. Saris, Appl. Phys. A 58, 493 (1994).

16. F. Brensheidt, E. Wieser, W. Matz. A. Mücklich, and W. Möller, Appl. Phys. A 65, 281 (1997).

17. F. Brensheidt, S. Oswald, A. Mücklich, E. Wieser, and W. Möller, Nucl. Instr. Meth. B 129, 483 (1997).

18. L.M. Wang, S.X. Wang, W.L. Gong, R.C. Ewing, and W.J. Weber, Mater. Sci. Eng. A 253, 106 (1998).

19. C.-M. Wang, X. Pan, M. Rühle, F.L. Riley, and M. Mitomo, J. Mater. Sci. 31, 5281 (1996).

20. J.F. Ziegler, J.P. Biersak, and U. Littmark, The Stopping and Range of Ions in Solids (Pergamon Press, New York, 1985).

21. F. de Brito Mota, J.F. Justo, and A. Fazzio, Phys. Rev. B 58 (13), 8323 (1998).

22. H.M. Naguib and R. Kelly, Radiat. Eff. 25, 1 (1975).

23. H. Abe, S. Yamamoto, and H. Naramoto, Nucl. Instr. Meth. B 127/128, 170 (1997).

24. R. Devanathan, K.E. Sickafus, W.J. Weber, and M. Nastasi, Nucl. Instr. Meth. B 141, 366 (1998).

25. L.W. Hobbs, A.N. Sreeram, C.E. Jesurum, and B.A. Berger, Nucl. Instr. Meth. B 116, 18 (1996).

26. S.J. Zinkle, in Microstructure Evolution During Irradiation, MRS Symposium Proceedings, edited by I.M. Robertson. G.S. Was, L.W. Hobbs, and T. Diaz de la Rubia (Materials Research Society, Pittsburgh, 1997), Vol. 439, p. 667. 